\title{
AC Impedance Studies on Metal/Nanoporous Silicon/p-Silicon Structures
}

\author{
M.F. MABROOK ${ }^{1,3}$ and A.K. RAY ${ }^{2,4}$ \\ 1.-School of Electronic Engineering, Bangor University, Bangor LL57 1UT, UK. 2.-Institute of \\ Materials and Manufacturing, Brunel University, Uxbridge, Middlesex UB8 3PH, UK. 3.-e-mail: \\ m.f.mabrook@bangor.ac.uk. 4.—e-mail: asim.ray@brunel.ac.uk
}

\begin{abstract}
Alternating current (AC) impedance measurements have been performed on $10-$ to $15-\mu \mathrm{m}$ thick porous silicon layers on a (100) $p$-type silicon $(p(+) \mathrm{Si})$ substrate with the aluminium $(\mathrm{Al})$ top electrode in a sandwich configuration in the range of $20 \mathrm{~Hz}-1 \mathrm{MHz}$ and in the temperature ranging between $152 \mathrm{~K}$ and $292 \mathrm{~K}$. The ac conductivity $\sigma_{\mathrm{ac}}$ was found to increase with frequency $f$ according to the universal power law: $\sigma_{\mathrm{ac}}=A f^{s}$ where the exponent $s$ is a frequency and temperature-dependent quantity. A hopping process is found to be dominant at low temperatures and high frequencies, while a thermally activated free band process is responsible for conduction at higher temperatures. Capacitance is found to decrease with frequency but increase with temperature. Frequency dependence of the loss tangent is observed with a temperature-dependent minimum value.
\end{abstract}

Key words: Free band conduction, activation energy, resistance-capacitance networks, loss tangent

\section{INTRODUCTION}

Porous silicon (PS) has attracted considerable interest over the last 20 years from both academic and industrial research communities for its luminescence (EL) properties because of the large surface to volume ratio. ${ }^{1}$ Investigations have also been carried into this PS material for its potential applications in the field of optoelectronics, ${ }^{2,3}$ drug delivery, $^{4}$ gas and biosensors ${ }^{5,6}$ and biomedical devices. ${ }^{7}$ The study of electrical properties of PS layers therefore becomes important to exploit these developments with further success. Current-voltage $I(V)$ characteristics of metal/PS/silicon ( $\mathrm{Si}$ ) structures have been found to be influenced by the type of metal contact. Sputtered platinum film forms an Ohmic contact with the PS while the Schottky barrier exists between copper $(\mathrm{Cu})$ and PS film. ${ }^{8}$ No major changes in Fourier transform infrared (FTIR) absorption peaks have been observed for the native PS in the Shottky diode structure formed between 10-nm and 40-nm-thick

(Received August 31, 2016; accepted November 10, 2016; published online November 28, 2016) radio $\mathrm{RF}$ magnetron sputtered $\mathrm{Cu}$ film and $\mathrm{PS}$. Values of the barrier height and the ideality factor were found to be $0.678 \mathrm{eV}$ and 2.77 , respectively from the $I(V)$ characteristics. ${ }^{9}$ Good rectifying behavior is observed in the $I(V)$ characteristics recorded for a palladium $(\mathrm{Pd}) / \mathrm{PS} / p$-Si structure with the ideality factor increasing from 3.1 to 3.5 at the small forward bias of $0.3 \mathrm{~V}$ as the PS layer thickness is varied from $30 \mathrm{~nm}$ to $90 \mathrm{~nm}$. There exists a $3-\mathrm{nm}$ thick interface layer between $\mathrm{Pd} / \mathrm{PS}$ and voltage redistribution between the interface, $\mathrm{PS}$ and $\mathrm{P}-\mathrm{Si}$ occurs with the PS thickness. ${ }^{10}$ Tunnelling via migration/diffusion is believed to be responsible for charge transport in an $\mathrm{Al} / \mathrm{PS} / p(+)-\mathrm{Si} / \mathrm{Al}$ structure which exhibits an ideality factor very close to unity, a high barrier height in the order of $0.63 \mathrm{eV}$ and a small series resistance of $30 \Omega .^{11}$

Impedance spectroscopy, measuring the $\mathrm{AC}$ electrical response over a wide frequency range, can predict the conductivity, structural homogeneity and stability considering the relative contributions of grain, grain boundary and defect states in thinfilm materials. ${ }^{12}$ This non-destructive AC impedance technique has been successfully employed to 
examine the surface morphology of macroporous silicon samples, providing the values of $1.52 \mu \mathrm{m}$ and $54.2 \%$ for the sample pore radius and porosity, respectively. There exists a good agreement within $2 \%$ accuracy between these results and the values obtained from conventional methods such as SEM and gravimetric analysis. ${ }^{13} \mathrm{AC}$ measurements on gold $(\mathrm{Au}) / \mathrm{PS} / p$-Si/Al using the $\mathrm{DC}$ bias voltage between \pm 2 V have been made at room temperature only and over the frequency range of $5 \mathrm{~Hz}-10 \mathrm{kHz}$. The structure exhibits conductor-type behavior for the bias voltage up to $0.5 \mathrm{~V}$ while the diode-type conduction becomes dominant at the medium frequency range. ${ }^{14}$

We report the results of $\mathrm{AC}$ conductivity and capacitance measurements on the $\mathrm{Al} / \mathrm{PS} / p(+) \mathrm{Si} / \mathrm{Al}$ structure in the frequency range of $20 \mathrm{~Hz}-1 \mathrm{MHz}$ and over the temperature range of 152-292 K. Our steady state current transport measurements on similar structures at relatively low bias voltages indicate that the rectifying behavior is similar to the one observed for an ideal $p-n$ junction. PS films behave like $n$-type $\mathrm{Si}$ due to their depletion of majority hole carriers. ${ }^{15}$ An equivalent circuit has been proposed in this investigation, taking the passive components of both bulk and junction regions into account. The data has been analyzed in terms of the universal power law and $240 \mathrm{~K}$ has been found to be a critical temperature for charge transport. The hopping mechanism became dominant at temperatures below $240 \mathrm{~K}$, while band-type conduction was observed above this temperature.

\section{EXPERIMENTAL}

PS layers were prepared by the anodization of (100) $p$-type silicon substrates in a 1:1 solution of HF acid (49\% in water) and ethanol at a current density of $30 \mathrm{~mA} / \mathrm{cm}^{2}$ for $20 \mathrm{~min}$ in the dark. Experiments were performed with substrates having different resistivities in the range between $8 \Omega \mathrm{cm}$ and $12 \Omega \mathrm{cm}$. Before anodization, Ohmic contacts were deposited on the back side of the wafers by $\mathrm{Al}$ evaporation followed by annealing at $625 \mathrm{~K}$ for $30 \mathrm{~min}$. The thickness of the PS layers made under the same fabrication conditions were estimated to be in the range of $10-15 \mu \mathrm{m}$. Following anodization, the samples were rinsed in deionized water for $15 \mathrm{~min}$, dried and transferred to a vacuum chamber to deposit thin Au contacts onto the PS surface through a mask. The metal evaporation was performed at a glancing angle between the molecular beam and the wafer in order to prevent the direct contact between the $p$-type silicon substrate and the metal. The active area $A$ of the device is $2 \mathrm{~mm}^{2}$. AC conductance and capacitance of the samples were measured in the frequency range between $20 \mathrm{~Hz}$ and $10^{6} \mathrm{~Hz}$ using HP 4276A LCR meter in a microprocessor-controlled system. The amplitude of the alternating signal was $100 \mathrm{mV}$ peak-to-peak with no DC bias. All measurements were taken inside a vacuum system at a pressure of approximately $10^{-3} \mathrm{~Pa}$.

\section{RESULTS AND DISCUSSION}

The experimental results were analyzed in order to determine the influence of temperature on the charge transport mechanism and dielectric behavior of $\mathrm{Au} / \mathrm{PS} / p-\mathrm{Si} / \mathrm{Al}$ structures. Electrical measurements on these structures at different temperatures are important because of expected variations in pore dimensions. ${ }^{16}$ New information has been elucidated from careful comparison of values of physical parameters estimated in this investigation with published data.

\section{Dependence of Conductivity on Frequency and Temperature}

A set of reproducible AC spectra in Fig. 1 shows the frequency $f$ dependence of $\mathrm{AC}$ conductivity $\sigma_{\mathrm{ac}}(f, T)$ at six temperatures $T$ in the range of $152 \mathrm{~K} \leq T \geq 292 \mathrm{~K}$. The spectra display three principal features, identified by threshold frequency $f_{\text {th }}=10 \mathrm{kHz}$ and transition temperature $T_{i}=$ $200 \mathrm{~K}$. The first regime is related to the low frequency $(f \leq 10 \mathrm{kHz})$ but high temperature $(T \geq 200 \mathrm{~K})$. As the temperature is raised, the conductivity becomes progressively less dependent upon frequency for $f \leq 10 \mathrm{kHz}$. The conductivity at room temperature is found to be nearly independent of frequency. Secondly, the conductivity exhibits a significant frequency-dependent behavior at low temperatures $T_{i} \leq 200 \mathrm{~K}$. This rise $\sigma_{\mathrm{ac}}$ with increasing $f$ at a given $T$ can be written in a universal power law form ${ }^{17}$ :

$$
\sigma_{\mathrm{ac}}(f, T)=\sigma_{\mathrm{dc}}+A f^{s}
$$

where $A$ is a complex constant. The exponent $s$ is dependent upon frequency and temperature.

As shown in Fig. 2, the variation of $s$ in Eq. 1 with respect to temperature indicates that there are two mechanisms responsible for the electrical conduction of porous silicon. For relatively high frequencies between $1 \mathrm{kHz}$ and $100 \mathrm{kHz}$, there is a nearly linear dependence of conductivity on frequency with the exponent $s$ lying in the range of $0.6 \leq s \leq 1$. The values are greater at high frequencies between $1 \mathrm{kHz}$ and $100 \mathrm{kHz}$ than those at relatively low frequencies in the range of $100 \mathrm{~Hz}-1 \mathrm{kHz}$ for a specific temperature. However, the value of $s$ is found to decrease with increasing temperature in both cases For $s \leq 1$, hopping of charge carriers between randomly distributed localized states through the PS layer is believed to be responsible for this behavior. ${ }^{18}$ The third regime refers to the low-frequency regime for which $s \leq 0.5$. The dependence of $\sigma_{\mathrm{ac}} \infty f^{0.5}$ for the $\mathrm{Al} / \mathrm{Ps} / \mathrm{Si}$ structure has been attributed to activated hopping in a fractal network. The low-frequency regime is governed by the fractal properties of porous $\mathrm{Si}$, whereas the 


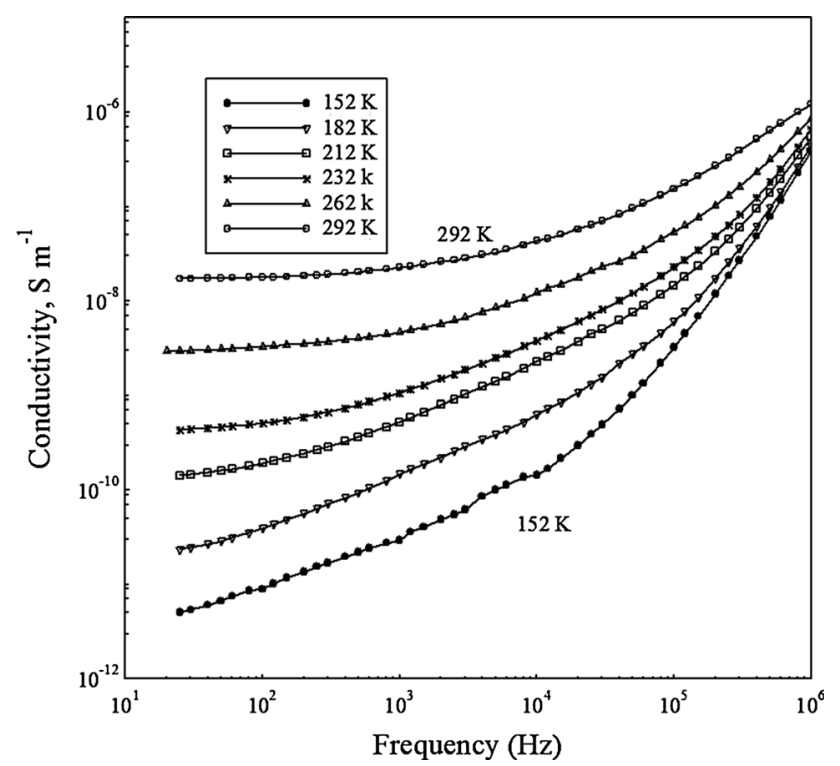

Fig. 1. Frequency dependence of $\mathrm{AC}$ conductivity $\sigma_{\mathrm{ac}}$ at six temperatures $T$ in the range of $152-292 \mathrm{~K}$ for the Al/PS/p(+)Si/Al structure.

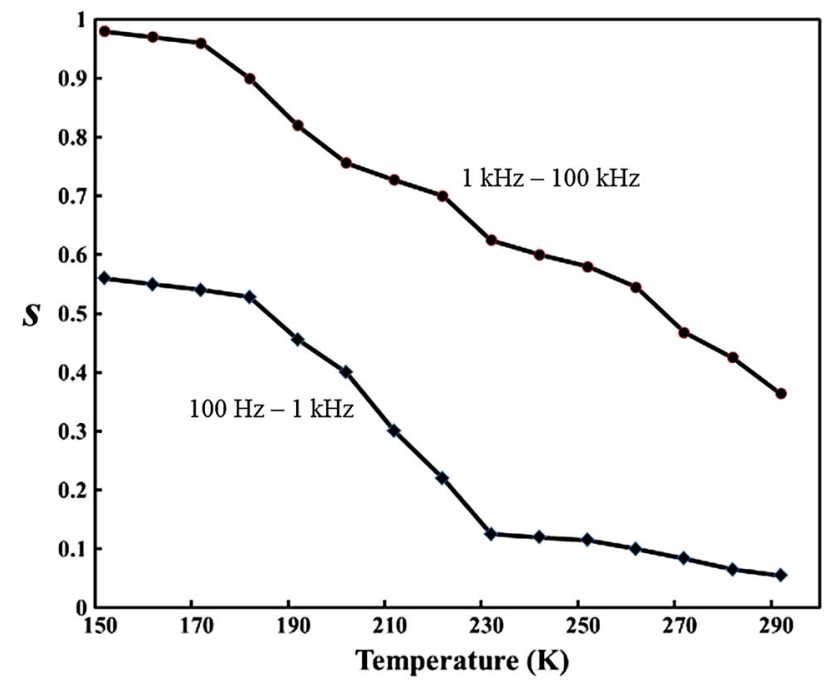

Fig. 2. Dependence of the exponent $s$ of the universal power law on temperature at two frequency ranges: (i) $10^{2} \mathrm{~Hz} \leq f \leq 1 \mathrm{kHz}$ and (ii) $1 \mathrm{kHz} \leq f \leq 100 \mathrm{kHz}$ for the same structure as in Fig. 1.

high-frequency dispersion is believed to have arisen from a broad distribution of activation energies. ${ }^{19}$ Assuming simple percolation like clusters of $\mathrm{Si}$ nanocrystals, the one-dimensional tight binding model has been further proposed for interpretation of power law dependence with $s<1$ in the highfrequency regime. ${ }^{20}$

The temperature dependence of the AC conductivity $\sigma_{\mathrm{ac}}$ is also presented in Fig. 3a at six different frequencies between $20 \mathrm{~Hz}$ and $1 \mathrm{MHz}$. The variation of DC conductivity with temperature is also included for the sake of comparison. The conductivity reaches a frequency-dependent saturated value
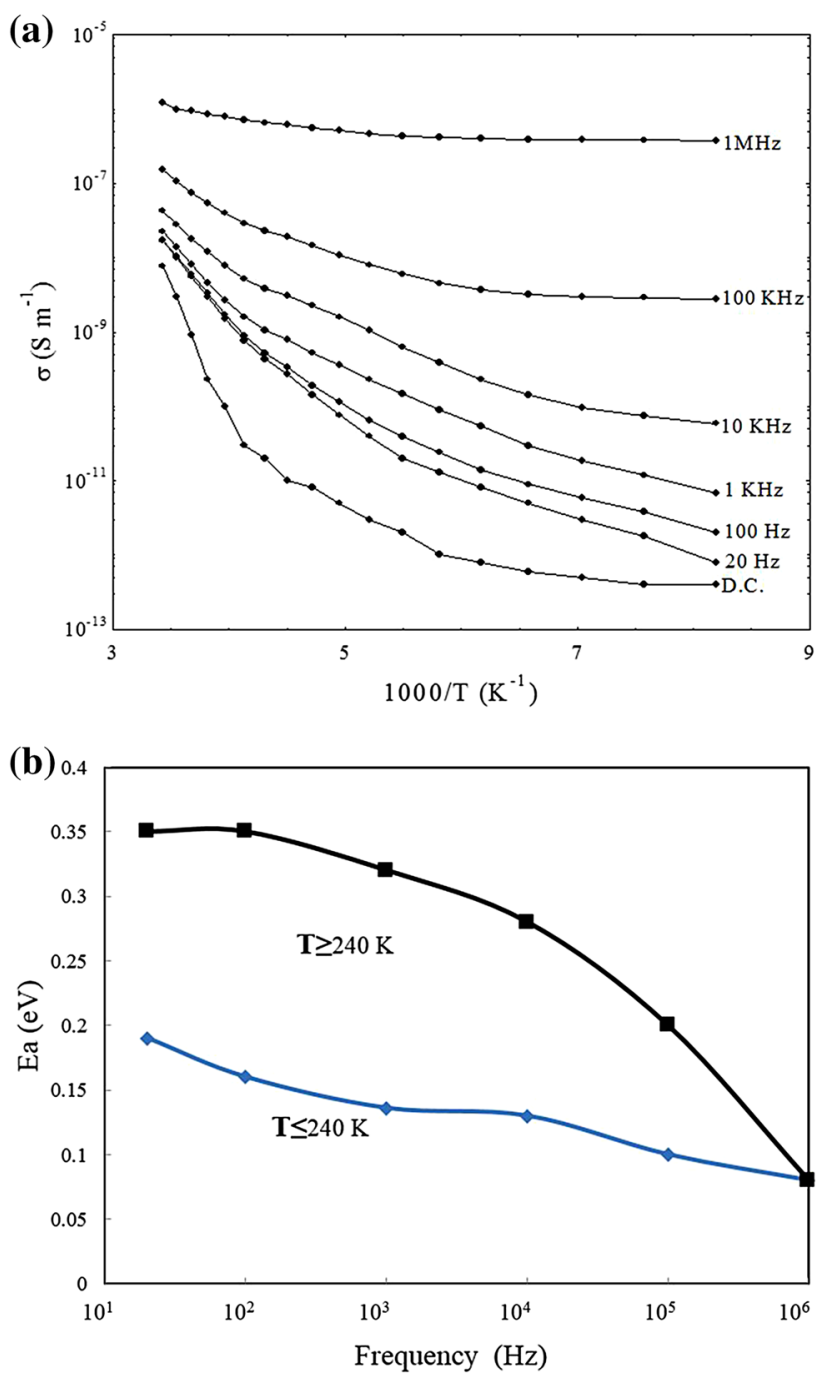

Fig. 3. (a) Arrhenius plot of $A C$ conductivity for six frequencies and (b) dependence of activation energy on frequency for $T<240 \mathrm{~K}$ and $T>240 \mathrm{~K}$.

below a transition temperature, the value of which increases with increasing frequency. For example, the conductivity becomes nearly constant at $154 \mathrm{~K}$ and $200 \mathrm{~K}$,corresponding to $100 \mathrm{kHz}$ and $1 \mathrm{MHz}$, respectively. The AC conductivity $\sigma_{\mathrm{ac}}$ is believed to increase exponentially with the temperature $T$ in the Arrhenius equation form ${ }^{21}$ :

$$
\sigma_{\mathrm{ac}}=\sigma_{0} \exp \left(-E_{\mathrm{a}} / k T\right)
$$

where $\sigma_{\mathrm{o}}$ is the value of $\sigma_{\mathrm{ac}}$ at $1 / T=0$ and $k$ is Boltzmann's constant.

Values of activation energy $E_{\text {a }}$ were estimated from the slopes in Fig. 3a for two regimes separated by the temperature of $240 \mathrm{~K}$ and their dependence on frequency is shown in Fig. 3b. The activation energy is found to be frequency-dependent and tends to decrease with the increasing frequency. However, the decrease of $E_{\mathrm{a}}$ is much sharper for $T>240 \mathrm{~K}$ than for $T<240 \mathrm{~K}$. Values of 0.35 and 
$0.2 \mathrm{eV}$ were obtained from Eq. 2 at $20 \mathrm{~Hz}$ corresponding to high- and low-temperature regimes. These results imply a free band conduction process at low frequency resulting from carriers exited from energy levels within the forbidden gap. ${ }^{22}$

\section{Dependence of Capacitance on Frequency and Temperature}

The variation in capacitance with frequency $(20 \mathrm{~Hz}-1 \mathrm{MHz})$ at various temperatures for the same PS sample is shown in Fig. 4. At temperatures $T_{i} \leq 182 \mathrm{~K}$, the capacitance is independent of frequency, whereas the capacitance for $T_{i} \geq 182 \mathrm{~K}$ initially decreases rapidly with increasing frequency. A similar pattern of constant capacitance behavior for $\mathrm{Au} / \mathrm{PS} / p-\mathrm{Si} / \mathrm{Al}$ structures over $10^{2} \mathrm{~Hz}$ and $10^{4} \mathrm{~Hz}$ is explained in terms of an equivalent circuit consisting of an inherent capacitance. ${ }^{23}$ The capacitance subsequently approaches the low temperatures value at high frequencies.

The capacitance is plotted in Fig. 5a as a function of temperature at four different frequencies. It can be seen that capacitance becomes independent of frequency in the low-temperature region. However, it begins to diverge as the temperature is raised above $200 \mathrm{~K}$. No Schottky barrier is believed to have existed at the interface between the porous silicon and the aluminium electrode. However, $\mathrm{Au} / \mathrm{PS} / p-\mathrm{Si} /$ $\mathrm{Al}$ may be treated as a heterojunction and the physical mechanisms at the $\mathrm{Au} / \mathrm{PS}$ and $\mathrm{PS} / p-\mathrm{Si}$ contacts need to be carefully considered for the interpretation of dielectric relaxation. ${ }^{24,25}$ As shown in Fig. 5b, this behavior may be explained in terms of an equivalent circuit comprising two parallel resistance-capacitance networks in series combination. The network of capacitance $C_{\mathrm{d}}$ and conductance $G_{\mathrm{d}}$ refer to the depletion region while $C_{\mathrm{p}}$ and $G_{\mathrm{p}}$ represent the geometrical capacitance and conductance, respectively, of the PS layer. The decrease of temperature may cause the transition between $C_{\mathrm{d}}$ and $C_{\mathrm{p}}$ at low frequencies, reducing the geometrical conductance of the PS layer. ${ }^{26}$

The admittance $Y$ is expressed in the form:

$$
Y=\frac{\left(G_{\mathrm{d}}+j \omega C_{\mathrm{d}}\right)\left(C_{\mathrm{p}}+j \omega C_{\mathrm{p}}\right)}{\left(G_{\mathrm{d}}+G_{\mathrm{p}}\right)+j \omega\left(C_{\mathrm{d}}+C_{\mathrm{p}}\right)}
$$

so the net conductance $G$ and net capacitance $C$ can be written in the form:

$$
G=\operatorname{Re}(Y)=\frac{G_{\mathrm{d}} G_{\mathrm{p}}\left(G_{\mathrm{d}}+G_{\mathrm{p}}\right)+\omega^{2}\left(G_{\mathrm{d}} C_{\mathrm{p}}^{2}+G_{\mathrm{p}} C_{\mathrm{d}}^{2}\right)}{\left(G_{\mathrm{d}}+G_{\mathrm{p}}\right)^{2}+\omega^{2}\left(C_{\mathrm{d}}+C_{\mathrm{p}}\right)^{2}}
$$

and

$$
C=\omega^{-1} \operatorname{Im}(Y)=\frac{C_{\mathrm{d}} G_{\mathrm{p}}^{2}+C_{\mathrm{p}} G_{\mathrm{d}}^{2}+\omega^{2} C_{\mathrm{d}} C_{\mathrm{p}}\left(C_{\mathrm{d}}+C_{\mathrm{p}}\right)}{\left(G_{\mathrm{d}}+G_{\mathrm{p}}\right)^{2}+\omega^{2}\left(C_{\mathrm{d}}+C\right)^{2}}
$$

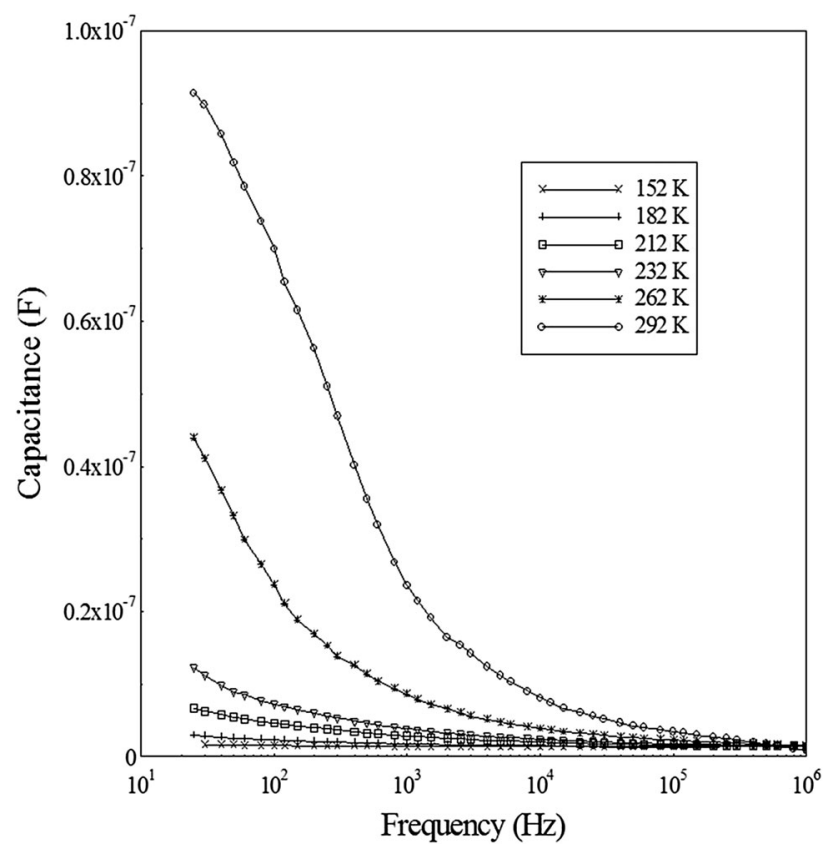

Fig. 4. Dependence of capacitance on frequency at different temperatures for the same structure as in Fig. 1.

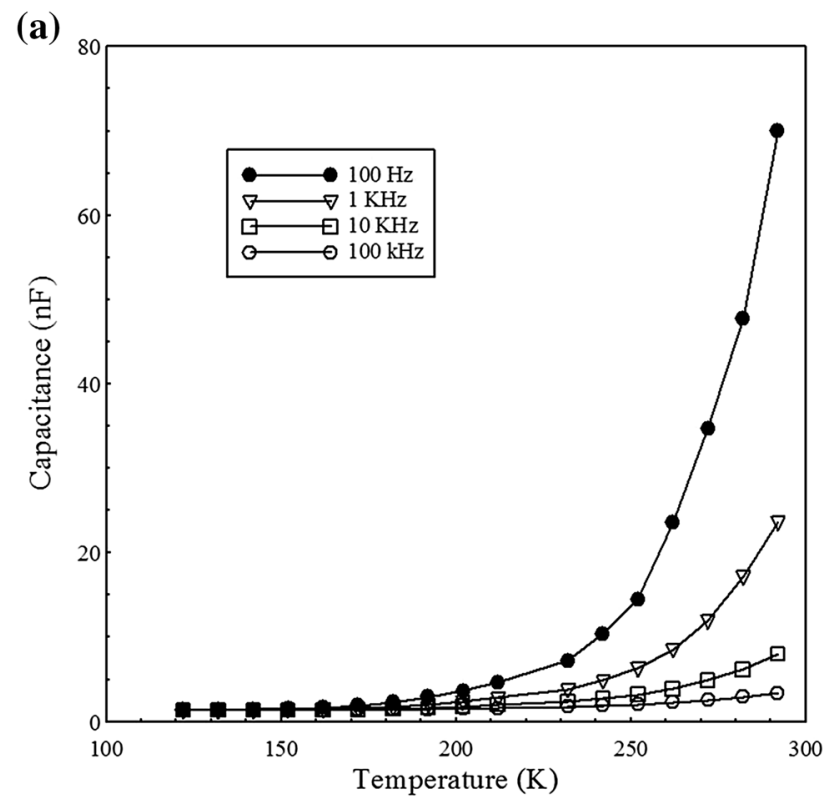

(b)

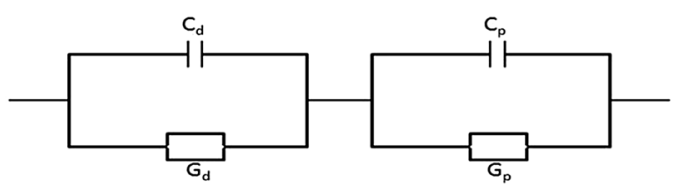

Fig. 5. (a) Temperature-dependence of capacitance at different frequencies and (b) equivalent circuit consisting of bulk and junction passive circuit parameters. 


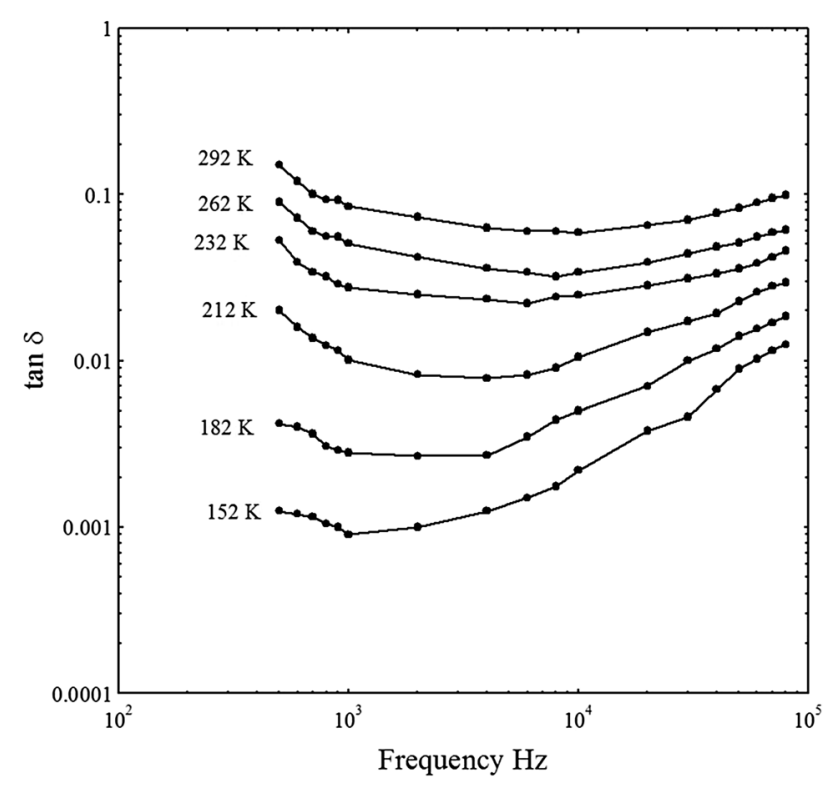

Fig. 6. Dependence of loss tangent on frequency at different temperatures.

The depletion capacitance $C_{\mathrm{d}}$ can be written in the form:

$$
C_{d}=A \sqrt{\frac{q p_{0} \varepsilon_{0} \varepsilon_{r}}{2 V_{0}}}
$$

$C_{\mathrm{p}}$ is taken to be independent of temperature and frequency since the PS layer is highly depleted in the first instance. It can also be assumed that $G_{\mathrm{d}} \gg G_{\mathrm{p}}$. With these approximations, Eqs. 4 and 5 can be written in the form:

$$
G=\frac{G_{\mathrm{d}}^{2} G_{\mathrm{p}}+\omega^{2} G_{\mathrm{d}} C_{\mathrm{p}}^{2}}{G_{\mathrm{d}}^{2}+\omega^{2}\left(C_{\mathrm{d}}+C_{\mathrm{p}}\right)^{2}}
$$

and

$$
C=\frac{C_{\mathrm{d}} G_{\mathrm{p}}^{2}+C_{\mathrm{p}} G_{\mathrm{d}}^{2}+\omega^{2} C_{\mathrm{d}} C_{\mathrm{p}}\left(C_{\mathrm{d}}+C_{\mathrm{p}}\right)}{G_{\mathrm{d}}^{2}+\omega^{2}\left(C_{\mathrm{d}}+C\right)^{2}}
$$

There are two limiting cases: for $\omega \rightarrow 0, G=G_{\mathrm{p}}$ and $C=\frac{G_{\mathrm{p}}^{2}}{G_{\mathrm{d}}^{2}} C_{\mathrm{d}}+C_{\mathrm{p}} . G=\frac{C_{\mathrm{p}}^{2}}{\left(C_{\mathrm{d}}+C_{\mathrm{p}}\right)^{2}} G_{\mathrm{d}}$ and $C=\frac{C_{\mathrm{d}} C_{\mathrm{p}}}{\left(C_{\mathrm{d}}+C_{\mathrm{p}}\right)}$ for $\omega \rightarrow \infty$. Using values of permittivity of free space $\varepsilon_{0}=8.85 \times 10^{-12} \mathrm{Fm}^{-1}$, dielectric constant $\varepsilon_{r}=11.9$ for silicon and the hole concentration $p_{0}=10^{-3}$ corresponding to the resistivity of $10 \Omega \mathrm{cm}$ for the $p(+) \mathrm{Si}$ substrate, $C_{\mathrm{d}}$ is found to be $22 \mathrm{nF}$. The porous silicon is completely depleted of holes so the value of $C_{\mathrm{p}}$ is estimated to be $15 \mathrm{nF}$ by replacing $V_{0}=E_{\mathrm{g}}=1.5 \mathrm{eV}$ in Eq. $8 . C_{\mathrm{d}}$ and $C_{\mathrm{p}}$ are found to be of the same order of magnitude.

Figure 6 shows the typical variation of the loss tangent $(\tan \delta)$ with frequency at temperatures $152 \mathrm{~K} \leq T \leq 292 \mathrm{~K}$ for the same device, where the angle $\delta$ is the phase angle of the impedance. It is clearly observed that $\tan \delta$ decreases with frequency and attains a minimum value $\left(\tan \delta_{\text {min }}\right)$ then slowly increases. The value is, however, smaller than one obtained for porous silicon oxynitride ceramics by a factor of four, indicating the suitability of its use as a low loss substrate. ${ }^{27}$ The position of $\left(\tan \delta_{\min }\right)$ is shifted to a higher frequency with increasing temperature. Residual electrolyte in the pores of a PS sample is reported to have influenced the dielectric spectrum. ${ }^{28}$ However, PS samples left for more than 3 months to dry exhibited the same conductivity behavior as the freshly made PS samples, implying that the residual electrolyte has no effect on AC conductivity of the PS samples.

\section{CONCLUSIONS}

An investigation of the frequency and temperature-dependence of the AC conductivity in PS suggests that the electrical conduction at low temperatures is essentially dominated by hopping of charge carriers through the PS layer. Free band conduction with activation energy of $0.35 \mathrm{eV}$ was observed for high temperatures and low frequencies. Capacitance was found to decrease with increasing frequency at high temperatures and frequency-independent at low temperatures. Loss tangent initially decreases with increasing frequency to reach a temperature-dependent minimum value and then start to increase slowly with frequency.

\section{ACKNOWLEDGEMENT}

Gratitude is due to Dr. Lesley Hanna of Brunel University, London, for her helpful and critical suggestions for improving the manuscript.

\section{OPEN ACCESS}

This article is distributed under the terms of the Creative Commons Attribution 4.0 International License (http://creativecommons.org/licenses/by/4.0/), which permits unrestricted use, distribution, and reproduction in any medium, provided you give appropriate credit to the original author(s) and the source, provide a link to the Creative Commons license, and indicate if changes were made.

\section{REFERENCES}

1. T. Roschuk, I.F. Crowe, A.P. Knights, and M.P. Halsall, Prog. Opt. 58, 251 (2013).

2. K.W. Cheah, L. Xu, and X. Huang, Nanotechnology 13, 238 (2002).

3. M. Atyaoui, W. Dimassi, G. Monther, R. Chtourou, and H. Ezzaouia, J. Lumin. 132, 277 (2012).

4. H. Hou, A. Nieto, F. Ma, W.R. Freeman, M.J. Sailor, and L. Cheng, J. Controll. Release 178, 46 (2014).

5. W. Yan, M. Hu, P. Zeng, S. Ma, and M. Li, Appl. Surf. Sci. 292, 551 (2014).

6. H.G. Kim and K.W. Lee, Sens. Actuat. B Chem. 219, 10 (2015).

7. A.A. Ensafi, M.M. Abarghoui, and B. Rezaei, Electrochim. Acta 123, 219 (2014).

8. P. Sun, M. Hu, B. Liu, F.Y. Su, and L.J. Xu, Acta Phys. Sin. 60, 057303 (2011).

9. S. Ghosh, K. Hong, and C. Lee, Mater. Sci. Eng. B Solid State Mater. Adv. Technol. 96, 53 (2002). 
10. V.A. Vikulov, V.I. Strikha, V.A. Skryshevsky, S.S. Kilchitskaya, E. Souteyrand, and J.R. Martin, J. Phys. D Appl. Phys. 33, 1957 (2000).

11. M. Gulnahar, T. Karacali, and H. Efeoglu, Electrochim. Acta 168, 41 (2015).

12. J.R. Macdonald, Impedance Spectroscopy-Emphasizing Solid Materials and Systems (New York: Wiley, 1987).

13. C. RoyChaudhuri, M. Jana, and N.R. Bandopadhyay, Phys. Status Solidi A Appl. Mater. 207, 2137 (2010).

14. F. Fonthal and M.A. Chavarria, Phys. Status Solidi C (2011). doi:10.1002/pssc.201000577.

15. A.K. Ray, M.F. Mabrook, and A.V. Nabok, J. Appl. Phys. 84, 3232 (1998).

16. R.S. Dariani and F. Tavakoli, Phys. B 456, 312 (2015).

17. A.K. Jonscher, Universal Relaxation Law (London: Chelsea Dielectric Press, 1996).

18. N.F. Mott and E.A. Davis, Electronic Processes in Non-Crystalline Materials, 2nd ed. (Oxford: Clarendon Press, 1979).
19. M. Ben-Chorin, F. Möller, F. Koch, W. Schirmacher, and M. Eberhard, Eberhard Phys. Rev. B 51, 2199 (1995).

20. H. Cruz, D. Luis, and N.E. Capuj, J. Appl. Phys. 83, 7693 (1998).

21. S.R. Elliot, Adv. Phys. 36, 135 (1987).

22. F. Fonthal, C. Goyes, and A. Rodriguez, Electron. Robot Automot. Mech. (2008). doi:10.1109/CERMA.2008.62.

23. M.E. Azim-Araghi and Z. Bisadi, Eur. Phys. J. Appl. Phys. 58, 20302 (2012).

24. M.A. Chavarria and F. Fonthal, 2009 Electronics Robotics and Automotive Mechanics Conference (2009), pp. 287-292. doi:10.1109/CERMA.2009.15.

25. M.A. Chavarria and F. Fonthal, ECS J. Solid State Sci. Technol. 5, P3172 (2016).

26. L.A. Balagurov, S.C. Bayliss, A.F. Orlov, E.A. Petrova, and B.D.G. Yarkin, J. Appl. Phys. 90, 4184 (2001).

27. S.J. Lin, F. Ye, S.L. Dong, J. Ma, B. Zhang, and J.J. Ding, Mater. Sci. Eng. A Struct. Mater. Prop. Microstruct. Process 635,1 (2015).

28. V.P. Parkhutik, Thin Solid Films 276, 195 (1996). 